\title{
PREPARATION, MICROSTRUCTURE EVALUATION AND PERFORMANCE ANALYSIS OF DIAMOND-IRON BONDED MAGNETIC ABRASIVE POWDER
}

\author{
Palwinder Singh, Lakhvir Singh, Sehijpal Singh
}

\begin{abstract}
The customary edged tool for machining is uneconomical for harder and hard to machine materials and furthermore the level of surface finish accomplished is not that great. As of late, a lot of consideration in mechanical engineering has been centered on finishing tasks. Not many investigations have been accounted for till date on the advancement of substitute magnetic abrasive powder (MAP). In this paper, to improve the finishing performance, the abrasive powder were prepared by mechanical alloying of diamond powder and iron $(\mathrm{Fe})$ powder, compacting these with universal testing machine (UTM) and then sintered at different temperature in a sintering machine in an inert gas (H2) atmosphere. These compacts were crushed and sieved to obtain various sizes of MAP. This abrasive powder were micro-structurally examined. The results indicate that the densification increases and porosity decreases with increasing temperature. Moreover, the prepared bonded MAP has potential performance as a new MAP for fine finishing in Magnetic Abrasive Flow Machining (MAFM) process.

Keywords: mechanical alloying, sintered, magnetic abrasive powder, diamond, Universal Testing Machine (UTM), bonded, Magnetic Abrasive Flow Machining (MAFM)
\end{abstract}

\section{INTRODUCTION}

There has been a quick development in the advancement of difficult and hard to machine materials and alloys during the most recent two decades. The standard edged tool machining is costly for these kind of materials and level of surface finish feasible is poor. As of late, a lot of consideration in mechanical engineering has been centered around finishing tasks went for fixing the finishing tolerance of machined segments. It is hard to finish propelled engineering materials with high exactness, and negligible surface imperfections, for example, small scale splits, by traditional grinding and cleaning procedures. To limit the surface harm, delicate adaptable finishing conditions are desirable, in particular, a low degree of controlled power. Magnetically assisted manufacturing processes are getting to be powerful in finishing, cleaning, deburring and shining of metal and propelled engineering material components. In perspective on the reality of this issue, as of late new unconventional fine machining techniques like Magnetic Float Machining (MFM), Magnetic Abrasive Polishing, Magnetic Abrasive Finishing (MAF) and Magnetic Abrasive Flow Machining (MAFM) have been developed.

Palwinder Singh: Research Scholar, IKGPTU, Kapurthala, India

Lakhvir Singh: Mech. Engg. Department, BBSB Engg. College, Fatehgarh Sahib, India

Sehijpal Singh: Mech. Engg. Department, Guru Nanak Dev Engg. College, Ludhiana, India 
Most of the existing studies throw light on the development of process and in the direction of enhancing the capabilities and applications of the process. However, the major constraint in wide spread adoption of this technology is the exorbitant cost of magnetic abrasives, which acts as a cutting tool in MAFM, not many investigations have been accounted for till date on the advancement of substitute magnetic abrasive powder.

Amir D. et al. [1] used unbonded $\mathrm{SiC}$ abrasives based media for the finishing of biomedical devices of stainless Steel 304. They reported that with increased MFD, the surface finish reduces. Also a fine surface finish was obtained with increased mesh number. Bahre et al. [2] employed AFM for machining of high strength steel AISI 4140 using $\mathrm{A} 12 \mathrm{O} 3$ abrasive based media and reported that higher piston pressure resulted in required surface finish. Butola et al. [3] investigated AFM process optimization for finishing of aluminum tube. The aluminum tube was finished by $\mathrm{Al}_{2} \mathrm{O}_{3}, \mathrm{SiC}$ and $\mathrm{B}_{4} \mathrm{C}$ abrasives based media. Khairy [4] prepared magnetic abrasive particles by blending of $\mathrm{Al}_{2} \mathrm{O}_{3}$ and $\mathrm{Fe}$ powders $(85 \%)$ compacting them, sintered the mixture in a furnace at $1400^{\circ} \mathrm{C}$ in inert atmosphere, crushing into small particles and sieving to obtain different sizes. Kreman et al. [5] developed magnetic abrasives by using the technique in which an adhesive is used to bind magnetic iron powder with $\mathrm{Al}_{2} \mathrm{O}_{3}$ powder. All the constituents were mixed, dried and crushed into small desired sizes for machining. Lin et al. [6] prepared magnetic abrasives by typically mixing $\mathrm{Fe}$ powder and $\mathrm{Al}_{2} \mathrm{O}_{3}$, compressed, sintered and crushed to produce average size 150 micrometer. Shinmura et al. [7] prepared two kinds of magnetic abrasives. The particle size of $\mathrm{Fe}$ in one and the particle size of abrasive particle in other was changed. The abrasive particle size affected stock removal comparatively less while surface roughness was significantly affected while iron particle size significantly affected both stock removal and surface finish. Singh and Shan [8] machined brass material by Brown Super Emery as magnetic abrasives to evaluate the performance of MAFM process. Sankar et al. [9] finished $\mathrm{Al}$ alloy based metal matrix composites (MMCs) by unbonded $\mathrm{SiC}$ abrasive particles in abrasive medium. They reported that Al alloy/SIC (10\%) MMC had better Ra amongst three workpiece materials. Sran et al. [10] prepared mechanically alloyed magnetic abrasives for finishing of brass tubes up to $3 \mathrm{~nm}$ level. Singh et al. [11] reported that annealing temperature effects the magnetic properties of the magnetic abrasives. It was reported that annealing/sintering temperature of $950{ }^{\circ} \mathrm{C}$ resulted in a maximum value of MFD. Yamaguchi et al. [12] developed spherical Fe based magnetic abrasive containing $\mathrm{Al}_{2} \mathrm{O}_{3}$ abrasives made by plasma spray technique. As the literature shows that most of the researchers had used unbonded abrasive particles in abrasive laden media for AFM or MAFM process. So preparation and performance evaluation of bonded magnetic abrasive powder in abrasive laden media needed to be investigated.

\section{EXPERIMENTAL DETAILS}

\section{Experimental set up for preparing magnetic abrasive powder}

The external photograph and schematic view of sintering machine is shown in Fig. 1 and Fig. 2 respectively. Sintering machine is an electric furnace in which specially designed stainless steel tube is used. The specimens of magnetic abrasive powder are placed in this tube and heated at given temperature ranges for 2 hours. Simultaneously $\mathrm{H}_{2}$ gas is passed through tube to create inert atmosphere. The main parts of sintering machine are:
a)
Electric Furnace $\left(\operatorname{Max} 1200^{\circ} \mathrm{C}\right)$
b) Thermocouple
c) Stainless Steel (AISI 310S) Tube 

d) Power Supply \& Control Unit of the Furnace
e) H2 Gas Cylinder
f) Pressure Regulator \& Pressure Gauges

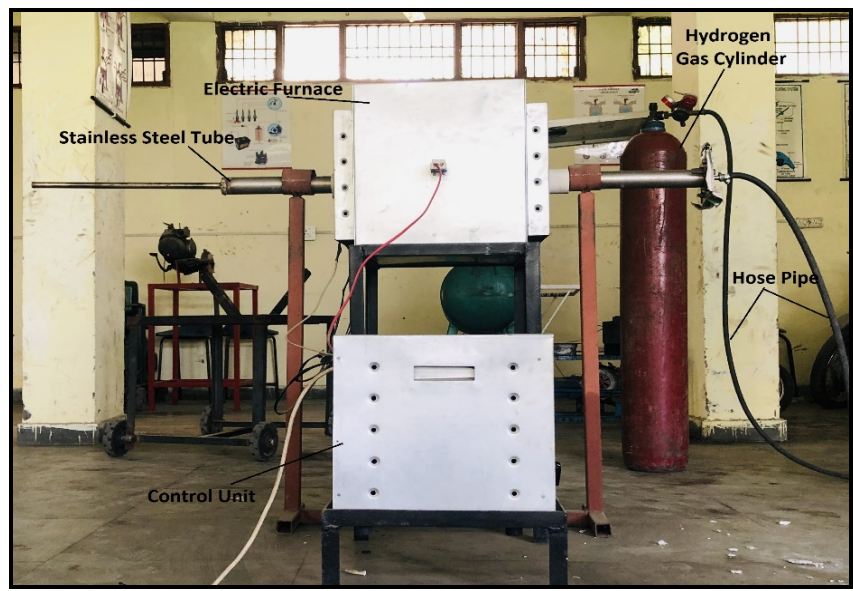

Fig.1. External view of sintering machine.

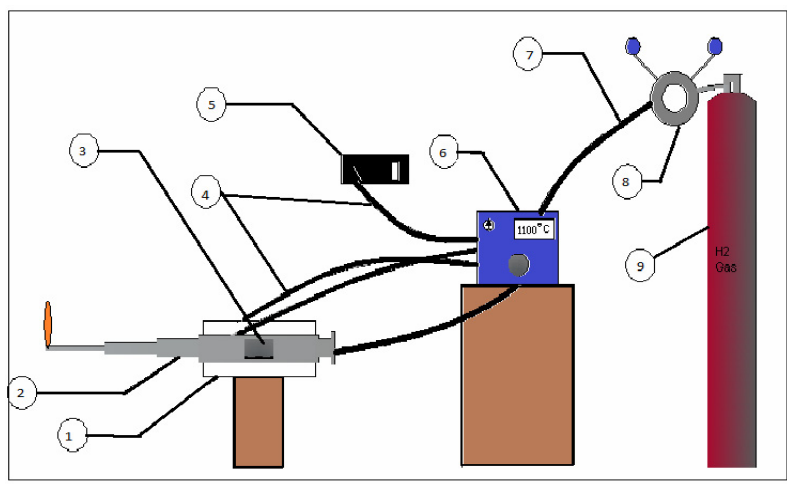

Fig. 2. Schematic view of sintering machine: 1. Furnace; 2. Stainless Steel (AISI 310) Tube; 3. Specimens for Sintering; 4.Power Cable; 5. Main Supply 220v; 6. Power Supply \& Control Unit of Furnace; 7. Hose Pipe for $\mathrm{H}_{2}$ Gas; 8. Pressure Regulator and Pressure Gauges; 9. $\mathrm{H}_{2}$ Gas Cylinder.

\section{Preparation of sintered magnetic abrasive powder}

The following procedure was adopted for the preparation of sintered magnetic abrasive powder:

* Mixing and mechanical alloying of Fe and diamond powders

* Preparing the compacts

* Sintering of compacts

Crushing of compacts and sieving 


\section{Mixing and mechanical alloying of iron and diamond powders}

The Fe powder and (300 mesh size) and diamond powder (270 mesh size) powders were mixed thoroughly in $70 \% \mathrm{Fe}+30 \%$ diamond proportion by volume percentage. This mixing was followed by mechanical alloying technique in which the powder particles were exposed to affect by high strength stainless steel balls in a ball mill/attritor at room temperature. After the process, very small MAPs are obtained in which the abrasive particles are connected to the base metal grid with no holding material.

\section{Preparation of compacts}

The compacts of $\mathrm{Fe}+$ diamond were prepared in cylindrical die by using Universal Testing Machine (UTM) in this work as shown in Fig. 3. The mixtures that is used here is mixed by the volume percentage i.e. $70 \% \mathrm{Fe}$ and $30 \%$ diamond proportion.

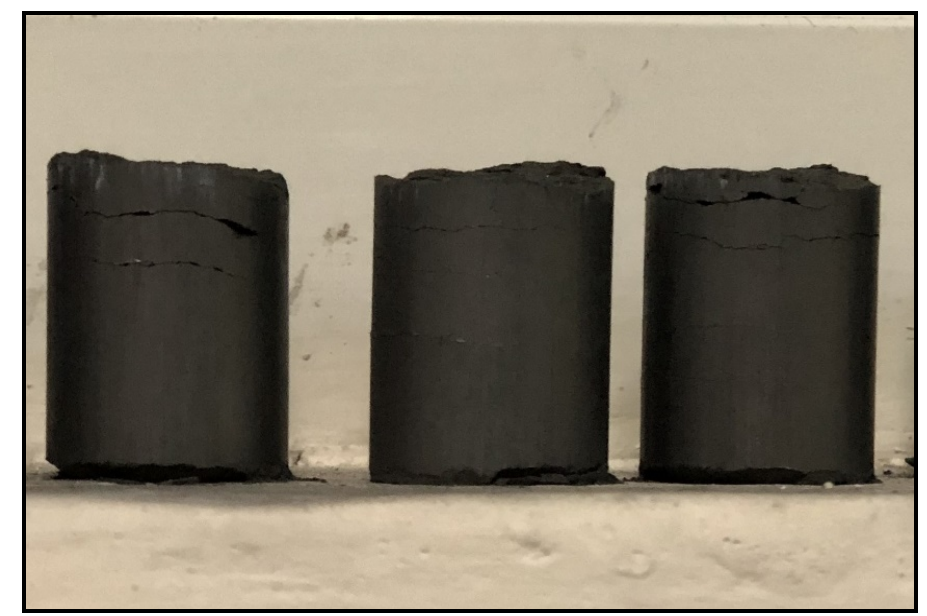

Fig.3. Compacts of mechanically alloyed magnetic abrasive powder.

\section{Sintering of compacts}

The compacts were placed within the stainless steel tube and were heated with the help of an electric furnace at temperature of $850^{\circ} \mathrm{C}, 950^{\circ} \mathrm{C}$ and $1050^{\circ} \mathrm{C}$. The furnace raised the temperature of the specimens up to $1050^{\circ} \mathrm{C}$ and simultaneously the $\mathrm{H}_{2}$ gas was supplied through hose pipe with suitable pressure that was indicated by the pressure gauges attached on the cylinder containing $\mathrm{H}_{2}$ gas for two hours. The pressure was controlled by pressure regulator. At last the furnace was switched off and sintering specimens were cooled at a very slow rate to refine the structure of the specimens. The hydrogen gas helps to produce improved surface crystalline, eliminates scaling, achieves optimum magnetic characteristics, and removes impurities like surface carbon, phosphorous. A nomenclature was given to three samples i.e. 30DFe850, 30DFe950 and 30DFe1050. Here 30D denotes percentage of diamond in iron, Fe denotes iron and 850, $950 \& 1050$ are the sintering temperatures. The sintered compacts are shown in Fig. 4. 


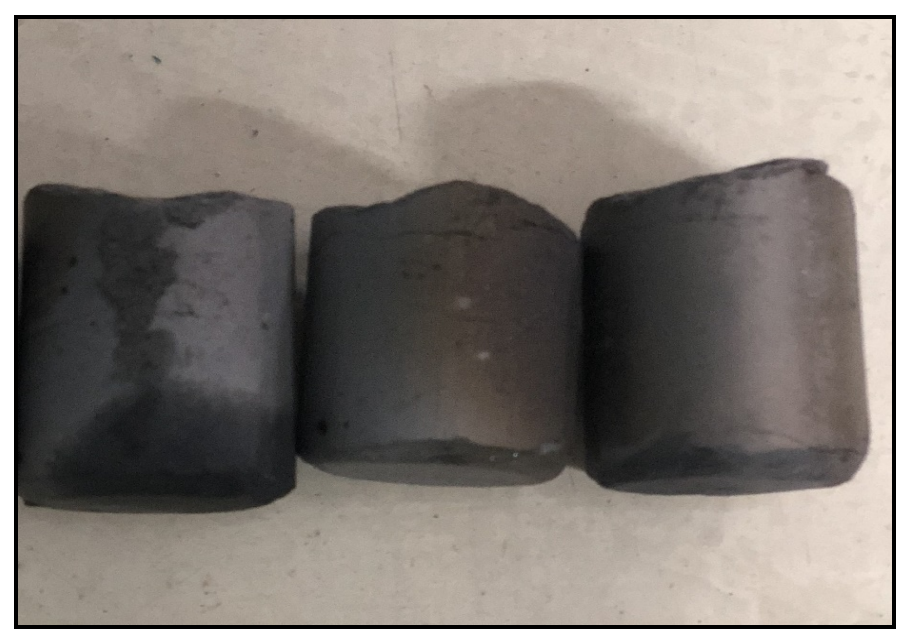

Fig.4. Sintered compacts.

\section{Crushing of compacts and sieving}

The sintered compacts were crushed mechanically into desired size. The sintered compacts were crushed into powder form. Then powdered abrasives were passed through different sieves to get different abrasive sizes. The obtained abrasive sizes were 200,275 and 350 mesh size.

\section{RESULTS AND DISCUSSION}

\section{Microstructure evaluation of prepared bonded magnetic abrasive powder}

To examine the sintering improvement of phase and microstructure, micrographs of the prepared magnetic abrasive powder was recorded utilizing scanning electron microscopy (SEM). The microstructure photographs of all the specimens' shows three types of grains, white ones are of diamond, black are of $\mathrm{Fe}$ and greyish are of $\mathrm{Fe}+$ diamond. The nano size particles of Fe+diamond were formed. The Fe+diamond formed in this case is due to reactive sintering between diamond and Fe particles. The various particles, i.e. of $\mathrm{Fe}$, diamond and iron+diamond, present in the microstructure have been marked on the photographs.

Figure 5 shows the microstructure of It can be clearly seen that with increase in temperature dense phase formation increases and porosity decreases. The specimen $30 \mathrm{DFe} 1050$ is denser in comparison to specimen 30DFe950 and 30DFe850. 


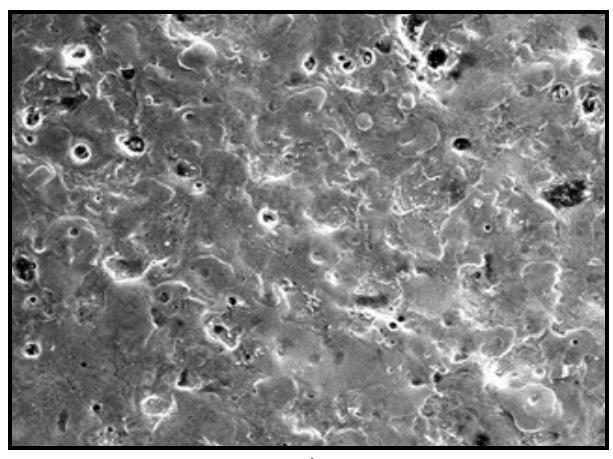

a)

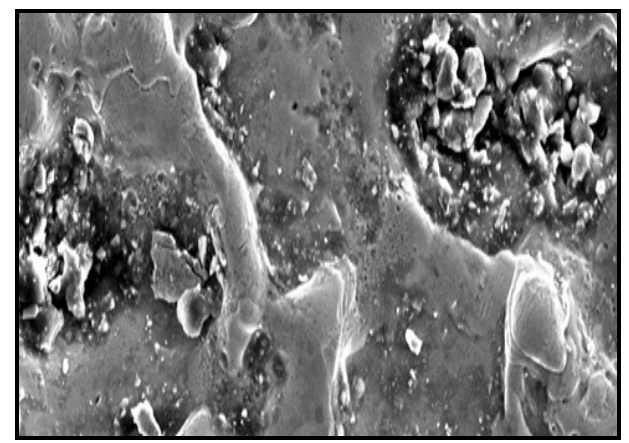

b)

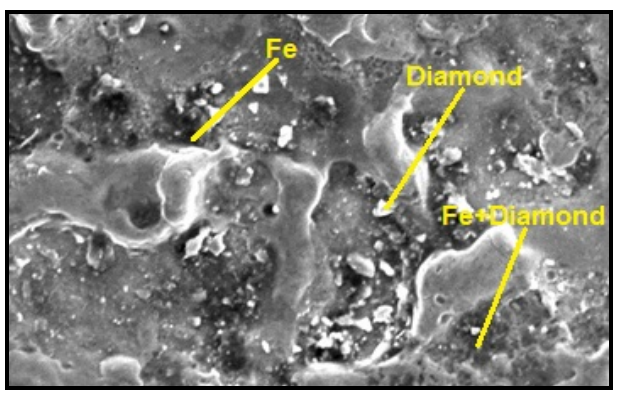

c)

Fig.5. Microstructure photos of a) 30DFe850, b) 30DFe950 and c) 30DFe1050.

\section{Performance analysis of prepared bonded magnetic abrasive powder}

The performance of prepared magnetic abrasive powder was evaluated in terms of SRIR (Surface Roughness improvement Rate) and MRR (material removal rate). The internal finishing of aluminum tubes was performed on magnetic abrasive flow machining (MAFM) set up (Fig. 6) using the prepared magnetic abrasive powder. The constant parameters were taken as 0.6 Tesla MFD (Magnetic Flux Density), 4.2 MPa extrusion pressure, 20 no. of cycles for evaluation. The work specimen to be machined/finished internally is hydraulically clamped in between the two media cylinders. Further two media cylinders are there in which the piston reciprocates by the motion of the hydraulic cylinders. The developed magnetic abrasive powder was mixed to form abrasive laden media, is filled in the lower chamber and then it is moved in the upward direction by the reciprocating drive given to the media cylinder piston. After completing the upward stroke the DC valve will operate in the other direction and the pistons will start coming downward, by pushing the media in the downward direction against the restrictions in the geometry of the fixtures to obtain the required pressure for abrasion to get finer finishing in the work piece.

As it can be clearly seen from the Fig. 7, that SRIR and MRR are higher at sintering temperature of $950^{\circ} \mathrm{C}$. The possible reason could be that the MFD was found to have highest effect at $950^{\circ} \mathrm{C}$ of annealing/sintering temperature [11]. Therefore, the prepared bonded magnetic abrasive powder has potential performance as a new magnetic abrasive powder for fine finishing. 


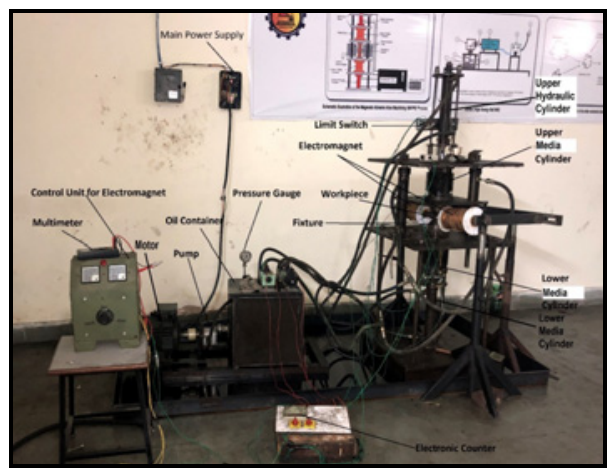

Fig.6. MAFM set up.

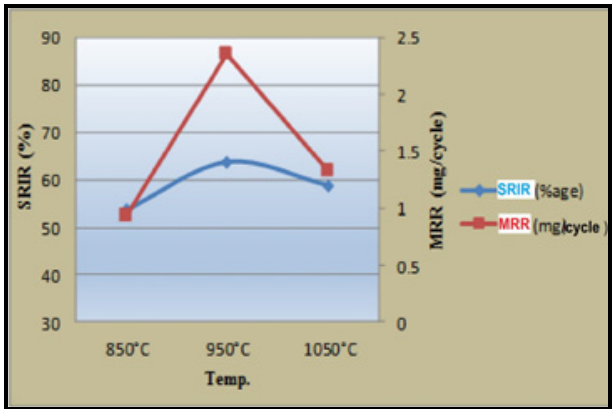

Fig. 7. Effect of sintering temperature on SRIR and MRR.

\section{CONCLUSIONS}

The conclusions drawn from this research work are summarized as follows:

1. The mechanical alloying followed by sintering of magnetic abrasive powder results in induced ductility, relieves internal stresses, refines the structure and increases the bonding strength of diamond $+\mathrm{Fe}$ abrasive powder.

2. The dense phase formation increases and porosity decreases with increase in sintering temperature.

3. The prepared bonded magnetic abrasive powder has potential performance as a new magnetic abrasive for fine finishing. The magnetic abrasive powder 30DFe950 delivered higher surface roughness improvement.

\section{Acknowledgement}

We hereby express our heartfelt thanks to department of RIC, IKGPTU and BBSBEC College for their continuous support.

\section{REFERENCES}

[1] Amir, D., Behzad, F., Behrouz, M., Navid, N.: Research and Development in Material Science, vol. 8, 2018, p. 1

[2] Bahre, D., Brunnet, H., Swat, M.: 5th CIRP Conf. High Performance Cutting, Procedia CIRP, vol. 1, 2012, p. 419

[3] Butola, R., Jain, R., Bhangadia, P., Bandhu, A., Walia, R.S., Murtaza Q.: Materials Today, Proceedings, vol. 5, 2018, p. 4720 
[4] Khairy, AB.: Journal of Materials Processing Technology, vol. 116, 2001, p. 77

[5] Kreman, G., Elsayed, E., Feygin, S., Lgelshteyn, L. In: Proceeding of International Machining and Grinding Conference. Vol. 3. Cincinnati, Ohio, 1999

[6] Lin, C., Tein, Y., Lieh, D., Chow, HM.: International Journal of Advance Manufacturing Technology, vol. 34, 2007, p. 122

[7] Shinmura, T., Takazawa, K., Hatano, E., Matsunaga, M.: Annals of the CIRP, vol. 39, 1990, p. 325

[8] Singh, S., Shan, HS.: International Journal of Machine Tools and Manufacture, vol. 42, 2002, p. 953

[9] Sankar, MR., Ramkumar J., Jain, VK.: Wear, vol. 266, 2009, p. 688

[10] Sran, LS., Khangura, SS., Singh, A. In: Proceeding of the ASME International Manufacturing Science and Engineering Conference. Notre Dame, Indiana, USA, 2012

[11] Singh, A., Singh, S., Singh, L.: International Journal of Advanced in Management, Technology and Engineering Sciences, vol. 7, 2017, no. 11, p. 246

[12] Yamaguchi, H., Kataro, H. (2008). Journal of Manufacturing Science and Engineering, vol. 130, 2008, p. 031107-1 